\title{
Neurophysiology of successful encoding and retrieval of source memory
}

\author{
Selene Cansino and Patricia Trejo-Morales \\ Universidad Nacional Autónoma de México, Mexico City, Mexico
}

\begin{abstract}
Event-related potentials were recorded during encoding, to identify whether brain activity predicts subsequent retrieval of spatial source information, and during retrieval, to investigate the neural correlates of successful and unsuccessful spatial context recollection. The amplitude registered during encoding for study items that were later recognized and assigned a correct source judgment was more positive than the amplitude for recognized items given incorrect source judgments; this difference started $480 \mathrm{msec}$ poststimulus, predominantly at central and anterior sites. During retrieval, the waveform was more positive from 250 to $1,600 \mathrm{msec}$ poststimulus when the brain had retrieved episodic information successfully than when it had failed. These findings indicate that brain electrical activity recorded during the first presentation of an item within its context predicts the subsequent retrieval of the specific spatial context. During retrieval, brain activity differed quantitatively at anterior sites and qualitatively at posterior sites according to the accuracy of source memory.
\end{abstract}

Shortly after the term "episodic memory" was introduced by Tulving (1972) to describe the memory that allows us to remember our own experiences, a dissociation began to be emphasized between two forms of retrieving episodic information - namely, that between "recollection" and "familiarity." These terms distinguish, respectively, episodic memory retrieved with or without the context information associated with the episode event when it was encoded. The phenomenological experience of remembering episodic information was introduced by Tulving (1985) when he described the "autonoetic" nature of episodic memory and provided empirical evidence via the "remember-know" paradigm. This procedure consists of asking subjects to express a "remember" response whenever they retrieve any contextual information referring to the study moment along with the item, and a "know" response when such contextual information is absent.

The remember-know procedure and other paradigms, such as those requiring recognition or retrieval of specific contextual information, have been extensively used to examine whether familiarity and recollection represent quantitatively or qualitatively different mnemonic processes (for a review, see Yonelinas, 2002). In addition to this question, increased research on episodic memory has provided evidence of different classes of retrieval processes. For example, Rugg and Wilding (2000) identified and described four retrieval processes, which they named "mode," "effort," "orientation," and "success" (see also Burgess \& Shallice, 1996). The present study focuses on the "success" process, which occurs as a preretrieval event and consists of successfully recovering relevant episodic information when the brain is engaged in a retrieval attempt (Rugg \& Henson, 2002).
Although several ERP studies have investigated memory for source information during encoding, most of these studies have compared the memory effects for correctly recognized items for which context was subsequently retrieved with those for items subsequently forgotten or missed (Duarte, Ranganath, Winward, Hayward, \& Knight, 2004; Friedman \& Trott, 2000; Mangels, Picton, \& Craik, 2001; Senkfor \& Van Petten, 1998; M. E. Smith, 1993), whereas in retrieval studies, items attracting correct source responses are usually compared with new items (Cycowicz \& Friedman, 2003; Johansson, Stenberg, Lindgren, \& Rosén, 2002; Johnson, Kounios, \& Nolde, 1997; Leynes, Bink, Marsh, Allen, \& May, 2003; Li, Morcom, \& Rugg, 2004; Mark \& Rugg, 1998; Rugg, Schloerscheidt, \& Mark, 1998; Senkfor, Van Petten, \& Kutas, 2002; A. P. R. Smith, Dolan, \& Rugg, 2004; Trott, Friedman, Ritter, \& Fabiani, 1997; Wegesin, Friedman, Varughese, \& Stern, 2002; Wilding, 1999, 2000; Wilding \& Rugg, 1996, 1997). These approaches do not allow for an analysis of brain activity related to the successful encoding and retrieval of source information only, since both familiarity and recollection processes are combined when brain responses for correct source judgments are compared with those for either subsequently missed or correct new items. Hence, to actually isolate brain activity related to recollection, it is necessary to compare correctly identified studied items retrieved with correct context with other items whose context was forgotten. This procedure provides clear evidence of brain responses that differ in the amount of source information initially encoded and finally recollected. Quantitative rather than qualitative electrophysiological differences between familiarity and recollection processes can be delineated with these comparisons, since 
other "noncritical" (Yonelinas \& Jacoby, 1996) contextual information can be recollected during incorrect source judgments. We adopted this approach in order to examine the neurophysiology of successful encoding and recollection of spatial contextual information by means of eventrelated potentials (ERPs), so as to characterize the temporal course of these processes as well as their topographical distribution. In particular, spatial context was studied because, along with the temporal context, it is considered one of the main characteristics of episodic memory (Gardiner \& Java, 1993 ) and is necessarily incorporated into any episodic event (Nadel, Ryan, Hayes, Gilboa, \& Moscovitch, 2003).

Successful recollection of episodic information depends to a great extent on the richness and strength of the initial encoding representation (Mayes \& Montaldi, 1999), and "subsequent memory effects" provide a useful approach for examining successful encoding of contextual information. These effects are observed when brain activity recorded during the encoding of stimuli is categorized according to whether items are subsequently retrieved, with or without contextual information. Few previous ERP studies have investigated this effect concerning source memory (Duarte et al., 2004; Friedman \& Trott, 2000; Mangels et al., 2001; Senkfor \& Van Petten, 1998; M. E. Smith, 1993), and their results have not been consistent. Four of these studies (Duarte et al., 2004; Friedman \& Trott, 2000; Mangels et al., 2001; M. E. Smith, 1993) employed the remember-know procedure. In the experiments by Friedman and Trott and Duarte et al., subjects were also asked to retrieve the list or the task context, respectively, in which each item was presented during the study phase. Senkfor and Van Petten used a recognition source memory task, in which subjects were requested to recognize whether a word was presented by the same voice (which could be male or female) as in the study session.

Apart from M. E. Smith (1993), all experiments that have employed the remember-know method have shown subsequent memory effects: The amplitude recorded for items subsequently termed "remember" was always more positive than that for items subsequently termed "know." However, Duarte et al. (2004) did not analyze their ERPs as a function of their source memory task, and the other two studies, which evaluated the recognition (Senkfor \& Van Petten, 1998) and retrieval (Friedman \& Trott, 2000) of a specific context, did not find subsequent memory effects for items whose source was correctly retrieved as compared with items for which the context was forgotten. Considering that source memory tasks represent an objective method to evaluate whether recognition memory is or is not accompanied by retrieval of contextual information-similar to the remember-know procedure, which rests, however, only on a subjective judgment based on the subject's introspection - one might expect subsequent memory effects to result from source memory tasks as in the remember-know procedure, especially when both methods are employed in the same study. In the Friedman and Trott study, the deviation from the expected results may be due to a low proportion of correct source responses (.49), which corresponds to a chance probability for a twochoice procedure $(p=.5)$. These data indicate that, in their study, the ERP waveforms for correct source judgments were mixed with those for lucky guesses. Duarte et al. found that approximately $55 \%$ of the items that attract a correct source response received a know judgment, whereas correct source responses were expected to be closely consistent with remember judgments, given that both categories are based on recollection processes. Senkfor and Van Petten did not observe subsequent memory effects, probably because they employed a recognition source memory task, which required less effort than a retrieval source memory task. In the former procedure, subjects may provide a correct source response for a recognized item merely because the context seems familiar to them, without needing to retrieve the real context.

The subsequent memory effect observed for remember as compared with know judgments (Duarte et al., 2004; Friedman \& Trott, 2000; Mangels et al., 2001) certainly provided the first evidence that the electrophysiological effects in the studies above have the sensitivity to predict the memory of the episode surrounding the item at the time of study. However, several questions still remain unsolved: What is the specific episodic information that leads subjects to provide a remember instead of a know response? Is a remember answer actually accompanied by a specific external or internal context, or did subjects base these responses on information from a combination of contexts, without actually being able to separate out the contribution of each different context to the episode? The interest in solving these questions is increased in light of the lack of correspondence between remember and correct source responses and between know and incorrect source responses in experiments that employed both tasks, in the rememberknow and source memory paradigm (Duarte et al., 2004; Friedman \& Trott, 2000). Thus, the question of the nature of the episode information that is predicted by the subsequent memory effects observed for the remember judgment remains open. Moreover, the extent to which memory for specific source information, and not only for remember items, generates the ERPs' subsequent memory effects also remains to be established. The first aim of the present study was to determine whether, at the time of study, neural activity associated with the successful encoding of specific contextual information could be identified.

In the present study, we employed a source memory paradigm (Cansino, Maquet, Dolan, \& Rugg, 2002) that included four possible contexts, instead of the more common approach of examining only two contexts. In the study phase, subjects were presented with color and perceptually rich images in one of four spatial locations. During the test, the subjects were requested to determine whether each presented item was new or old and, if it was old, the location at which it had been presented in the study phase. By using a four-choice source memory task, we reduced the probability that a correct source judgment could arise by chance $(p=.25)$ and increased the proportions of source judgments, both correct and incorrect, in order to perform more powerful contrasts between these conditions. We expected that, by employing a source memory task with high item recognition rates and source memory performance significantly above chance level, it would be possible to 
observe subsequent memory effects for spatial context. However, if these effects could not be observed, this would seem to indicate that the brain encodes, at least for the activity reflected by ERPs, the whole episode as mirrored by a remember judgment for which no specific source information is required, and that the brain activity related to spatial context encoding is not visible even when spatial source information is explicitly relevant to the task.

Direct comparisons of neural activity during the recognition of items retrieved with and without contextual information are absent in almost all previous ERP experiments employing a retrieval source memory task, because of the low proportion of incorrect source responses available for comparison. Thus, source memory recollection examined by this contrast has rarely been reported (Senkfor et al., 2002; Trott et al., 1997; Wilding, 1999; Wilding \& Rugg, 1996). It is important to note that one of these experiments employed two (Wilding \& Rugg, 1996), and another three, successive responses (Trott et al., 1997). In both of these studies, the source memory judgment was the last one made. Since brain activity was recorded before the source judgment, it is possible that the actual neural activity relating to source retrieval was not captured in the epochs analyzed in these experiments, as Cycowicz and Friedman (2003) have noted. The two previous studies that employed a source memory task without sequential responses reported more positive waveforms for correct than for incorrect source responses at posterior sites (Senkfor et al., 2002; Wilding, 1999), but only one of the studies observed these effects at anterior sites (Wilding, 1999).

A second aim of this experiment was to investigate the neural correlates of successful versus unsuccessful context retrieval by employing a source memory task without sequential responses. One issue from the two previous experiments that used such a procedure (Senkfor et al., 2002; Wilding, 1999) still remains unresolved: the identification of the scalp topography that characterizes the brain that successfully retrieves source information, given that neither of these studies reported scalp topographies for correct minus incorrect source judgments. The present study examines the scalp topography for the subtraction of these two response categories, which allows for unambiguously isolating the brain activity related to recollection, since familiarity processes are excluded from this subtraction. In addition, we explored the difference between incorrect source responses and correct "new" responses. This subtraction has been analyzed before, but scalp topographies were not available (Wilding, 1999). This contrast provides information concerning the neural correlates for recognized items with a lesser amount of contextual information, since during these trials subjects attempted to retrieve the "critical" source information but failed. Scalp topographies for correct source responses minus correct responses to new items will be examined in the present study as well. Although this contrast confounds recollection and familiarity processes, since both are included in a correct source judgment, the analysis of this contrast will allow us to compare the present results with findings from previous studies, given that this has been the classic comparison reported (Li et al., 2004; Mark \& Rugg, 1998;
Rugg et al., 1998; A. P. R. Smith et al., 2004; Trott et al., 1997; Wegesin et al., 2002; Wilding, 1999, 2000; Wilding \& Rugg, 1996, 1997). Moreover, the direct comparison of scalp topographies for recollection (correct minus incorrect source judgments) and "critical" source information forgetfulness (incorrect source responses minus correct "new" responses) will contribute to the essential issue of identifying whether distinctive patterns of neural activity underlie successful and unsuccessful spatial context retrieval. We hypothesized that scalp topographies will be quantitatively different for these processes; specifically, we presume that frontal activity will be more prominent in source recollection success than in failure, because of the enhanced frontal retrieval strategies necessary to recollect the spatial context (Fletcher \& Henson, 2001).

\section{METHOD}

\section{Subjects}

Twenty-four healthy right-handed subjects were paid to participate in the study, after providing informed consent. The experiment was approved by the Bioethics Committee of the School of Medicine of the Universidad Nacional Autónoma de México. The data from 7 subjects were excluded from the analysis: 2 of them because their recordings included numerous ocular artifacts, and 5 because their source accuracy was near chance (below $30 \%$ ). The mean age of the 17 remaining subjects ( 6 males) was 22.5 years $(S D=1.6)$, and their mean schooling was 10.8 years $(S D=1.2)$.

\section{Stimuli}

The same stimuli employed by Cansino et al. (2002) were used: 192 color images of common objects, 12 of which were used during a training session. Half of the images were representations of natural objects, the rest of artificial objects. From the pool of 180 images, different sets of 120 images were selected for use with each subject during the encoding session, whereas during the retrieval session the complete pool of 180 images was employed. Each stimulus subtended horizontal and vertical angles ranging between $2.9^{\circ}$ and $4.3^{\circ}$.

\section{Procedure}

The experiment consisted of an encoding and a retrieval session. Electrophysiological recordings were taken during both sessions in a sound-dampened chamber with dim illumination. Subjects were seated in a high-back armchair, $100 \mathrm{~cm}$ away from the monitor screen. Before the recordings, subjects participated in a training session in which they performed brief versions of the encoding and retrieval tasks. During this training session, subjects were familiarized with the response panel that was to be used during the experiments. It consisted of five push buttons: one was located in the lower part of the panel, to be pressed by the thumb, and the other four were arranged in two rows of two keys each. The left keys of each row were accessed by the index finger, whereas the right keys were pressed by the middle finger. This four-button array represented the four screen locations where images could be presented during encoding. During the encoding task, only the two keys of the lower row were employed, whereas in the retrieval task all of the keys on the panel were used (see below). The encoding and retrieval tasks lasted approximately 9 and $14 \mathrm{~min}$, respectively. The interval between tasks lasted around $4 \mathrm{~min}$. During the encoding task, 120 stimuli were presented, whereas during the retrieval task, the same 120 stimuli were shown randomly intermixed with 60 new images. Experimental control and the collection of behavioral responses were managed using E-Prime software, Version 1.0, from Psychology Software Tools.

Source memory paradigm. During the encoding task, a cross was continuously displayed on the screen, dividing it into four quad- 
rants; the center of the cross was in the middle of the screen. To avoid eye movement artifacts, each trial began with the presentation of a small cross in one quadrant during $500 \mathrm{msec}$ as a fixation point (horizontal and vertical visual angles of $0.5^{\circ}$ ). Subjects were instructed to move their eyes to the quadrant where the cross appeared and to fix the eyes there for the rest of the trial. Immediately after the fixation point disappeared, the stimulus was displayed at the same place. During each run, the four positions of the screen were randomly selected with the same probability. The images were exhibited near the middle of the screen at a distance ranging between $0.5^{\circ}$ and $1.25^{\circ}$ from the vertical or horizontal axes of the cross that divided the screen. Each stimulus was displayed for $500 \mathrm{msec}$, and the interval between successive stimulus onsets was $4.5 \mathrm{sec}$. After the onset of each stimulus, subjects pressed one of two buttons on the response panel to signal whether the image represented an artificial or natural object. The subjects were instructed to blink only after they had chosen their response, for both the encoding and the retrieval sessions. As previously mentioned, before the recording session the subjects had participated in a training session in which they had learned about the retrieval task to follow. Thus, during encoding, they were instructed to concentrate on the judgment of whether the object was artificial or natural.

For the retrieval session, a small cross subtending horizontal and vertical angles of $0.5^{\circ}$ was displayed at the center of the screen for $500 \mathrm{msec}$, indicating the eyesight focusing point. Trials began once the cross had disappeared, with the presentation of the stimulus at the center of the screen for $500 \mathrm{msec}$. The interval between successive stimulus onsets was $4.5 \mathrm{sec}$. In this session, subjects were instructed to judge whether the image was new or old (i.e., whether or not it had been presented in the encoding session). When the image was judged new, subjects pressed the lower key on the response panel, and when it was judged old, they indicated the position on the screen at which it had been presented during the encoding session by pressing one of the four keys on the response panel, representing each of the four screen quadrants. Subjects were instructed to guess if they were unable to remember the position of the stimulus at the time of encoding.

ERP recording. ERPs were recorded with a Quik-cap (Compumedics NeuroScan) with sintered silver electrodes. Twenty-eight derivations were recorded, 6 from the midline $(\mathrm{Fz}, \mathrm{FCz}, \mathrm{Cz}, \mathrm{CPz}$, $\mathrm{Pz}$, and $\mathrm{Oz})$ and 11 from each cerebral hemisphere (F3, F4, FC3, FC4, C3, C4, CP3, CP4, P3, P4, O1, O2, F7, F8, FT7, FT8, T7, T8, TP7, TP8, P7, and P8). An electrode was placed on the forehead as a grounding electrode. The recording was monopolar with reference to linked earlobe electrodes. For the electrooculogram (EOG), a bipolar recording was performed by placing an electrode on the upper portion of the left eye to measure vertical movements, and another on the adjacent external portion of the right eye, at the level of the cornea, to measure horizontal movements. The impedance of all electrodes was below $5 \mathrm{k} \Omega$. The electroencephalogram (EEG) and the EOG were recorded and amplified 20,000 times using a GRASS Model 12 Neurodata Acquisition System. The recording bandwidth was between 0.1 and $100 \mathrm{~Hz}$, with rolloffs at $6 \mathrm{~dB} /$ octave and a $60-\mathrm{Hz}$ notch filter. The amplified activity was continuously digitized at a rate of $512 \mathrm{~Hz}$. The signal was digitally filtered offline with a zero-phase-shift low-pass filter at $20 \mathrm{~Hz}$. Epochs 2,200 $\mathrm{msec}$ in duration, which included a prestimulus baseline period of $200 \mathrm{msec}$, were created for the encoding and retrieval session recordings.

\section{Data Analysis}

Eye movements were corrected by a method that combines artifact averaging and regression analysis and is available in Neuroscan, Version 4.3 (Semlitsch, Anderer, Schuster, \& Presslich, 1986). Items attracting an incorrect response during the encoding task were excluded from the analyses of both the encoding and retrieval data. Physiological data were averaged individually and per group. Encoding data were averaged for images that were subsequently recognized, attracting both correct and incorrect source judgments. Retrieval data were averaged for correct new images, correct source responses, and incorrect source responses. The mean number of epochs for all categories was $26.3(S D=9.7$, range 16-57), and the number of epochs did not differ significantly among categories $[F(4,64)=1.31, p=.3$, $\varepsilon=.72]$. ERP mean amplitudes (in microvolts) were measured relative to the mean voltage during the $200-\mathrm{msec}$ prestimulus baseline. Components or amplitude deflections identified in the grand mean waveforms and in previous source memory experiments (Duarte et al., 2004; Friedman \& Trott, 2000; Mangels et al., 2001; Senkfor et al., 2002; Wilding, 1999) were measured. Some of the amplitude deflections may not have corresponded to traditional ERP components; however, this approach was adopted in order to exploit the high temporal resolution of the ERP technique and to establish as exactly as possible the latencies at which the differences between conditions started. Hence, to avoid a misclassification of a specific component, we will refer to each of them by indicating the latency of its maximum amplitude. The time windows employed and the measured components are depicted in Figure 1.

The first two components observed in the encoding and retrieval data peaked at 120 and $180 \mathrm{msec}$ and had negative and positive amplitudes, respectively, at frontal electrode sites, as well as the opposite polarities at posterior sites; at central electrode sites, only the 120 -msec component with negative polarity was evident. These two components were measured between 0 and $150 \mathrm{msec}$ and between 150 and $250 \mathrm{msec}$, respectively, in both the encoding and retrieval data. After these early components, four components were identified in the encoding data, with the following polarities and maximumamplitude latencies: a positive $350-\mathrm{msec}$ waveform, measured between 250 and $480 \mathrm{msec}$; a positive 600-msec component, between 480 and $730 \mathrm{msec}$; a negative 850 -msec component, between 730 and $950 \mathrm{msec}$; and a sustained positive wave that lasted almost until the end of the epoch, which was quantified across three successive time windows - 950-1,200, 1,200-1,600, and 1,600-2,000 msec. In the retrieval data, five components were observed subsequent to the two early components already described, with the following polarities and maximum-amplitude latencies: a positive 300-msec waveform, measured between 250 and $350 \mathrm{msec}$; a 430-msec negative component, between 350 and $470 \mathrm{msec}$; a positive $600-\mathrm{msec}$ waveform, between 470 and $800 \mathrm{msec}$; a negative 950-msec component, between 800 and 1,200 msec; and a sustained positive waveform that lasted almost until the end of the epoch, which was measured across two successive time windows - 1,200-1,600 and 1,600-2,000 msec.

Repeated measures ANOVAs were performed separately for the data from the encoding and the retrieval sessions. Initially, global ANOVAs were computed for each latency window, on data from the diverse response categories and from all 28 electrode sites. The factors considered for the encoding data were response category (subsequent correct and incorrect source responses) and electrode site (28 levels); the analyses for retrieval data included the two factors response category (correct "new" responses, correct source responses, and incorrect source responses) and electrode site (28 levels). Only the latency windows in which the analyses turned out to be significant for response category or the interaction between response category and electrode site were submitted to additional analysis, in order to provide more detail concerning the effects at specific sites, especially where the effects were more evident and where effects had been reported in previous source memory studies (Duarte et al., 2004; Mangels et al., 2001; Senkfor et al., 2002; Wilding \& Rugg, 1996). For the encoding data, this specific analysis included the factors response category (subsequent correct and incorrect source responses), anterior-posterior site (anterior: F7, F3, F8, F4; central: T7, C3, T8, C4; posterior: P7, P3, P8, P4), hemisphere (left: F7, F3, T7, C3, P7, P3; right: F8, F4, T8, C4, P8, P4), and inferior-superior (inferior: F7, F8, T7, T8, P7, P8; superior: F3, F4, C3, C4, P3, P4). The same factors were included in the specific analyses of retrieval data, except that the factor response category also comprised correct responses for new items, along with correct and incorrect source responses.

Scalp distribution analyses were performed in order to determine whether the topography of the distinctive memory effects changed over time. These analyses were conducted on rescaled data using the first procedure proposed by McCarthy and Wood (1985) in order to remove the confounding effects of global differences in magnitude. 

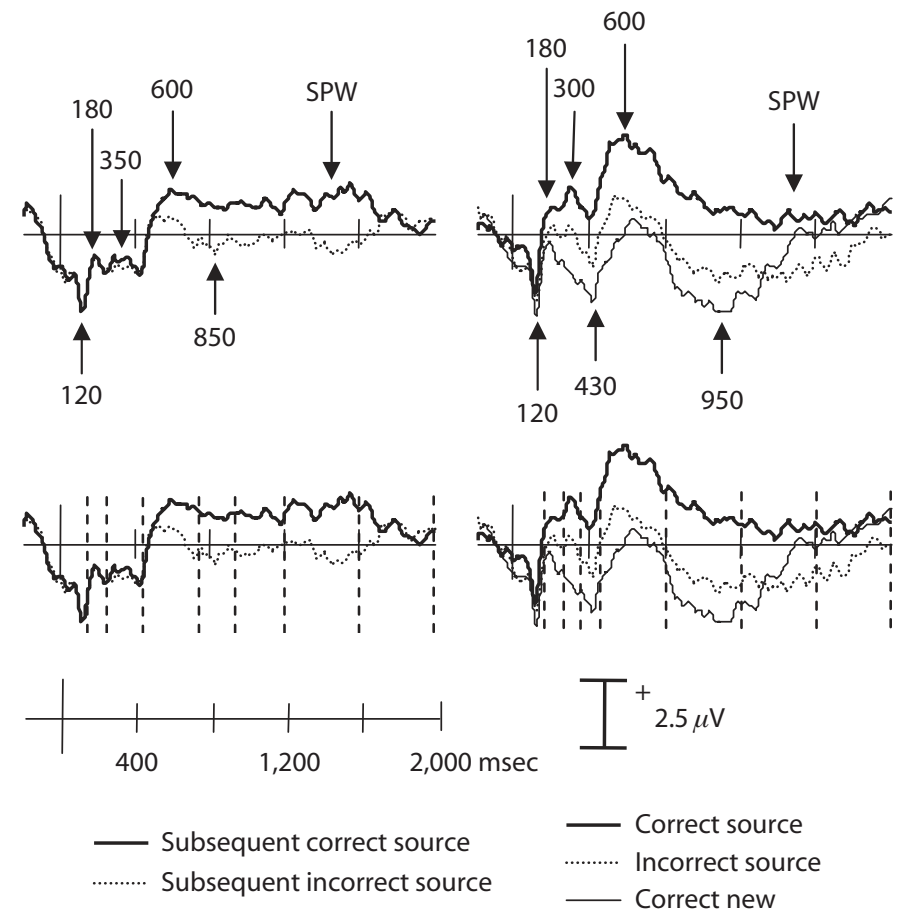

Figure 1. Grand average ERP waveforms registered at the left front electrode site (F7) during encoding (left) and retrieval (right). The recorded ERP components are labeled according to the latency (in milliseconds) of their maximum amplitude, except for the sustained positive wave (SPW) at the end of the epoch. Downward arrows indicate components with positive amplitude, and upward arrows those with negative amplitude. The same waveforms are shown in the bottom row, where the latency windows employed to measure the mean amplitude of each of the components are indicated with discontinuous lines.

Only the latency windows at which the effects found via ANOVA were significant were included in the topographic analyses. The analysis of the encoding data was conducted on the difference between subsequent correct and incorrect source judgments and included the factors latency window and electrode site (28 levels). For the retrieval data, three waveform differences - correct source responses - incorrect source responses, correct source responses - correct "new" responses, and incorrect source responses - correct "new" responseswere analyzed by pairs in three independent ANOVAs. This approach was adopted because the latency windows at which effects were significant in the specific analyses varied among the response categories. These analyses included the factors memory effect (two of the difference scores mentioned above), latency window with significant effect, and electrode site (28 levels). The results of these analyses are reported only when the effects involve electrode locations.

All significant ANOVAs were followed up by post hoc comparisons computed with the Tukey honestly significant difference (HSD) test. Effects that did not involve the factor response category are not described. Degrees of freedom were corrected using the Greenhouse-Geisser procedure in order to compensate for inhomogeneous covariance that might produce marked increases in Type I errors. For these cases, the original degrees of freedom, Greenhouse-Geisser coefficient $(\varepsilon)$, and corrected probability levels are reported. The significance level was $p<.05$.

\section{RESULTS}

\section{Behavioral Results}

Response accuracy during the encoding task was $97 \%$ $(S D=2.6)$, and the mean RTs at encoding for images sub- sequently attracting correct source responses $(915 \mathrm{msec}$, $S E=37$ ) did not differ from those subsequently attracting incorrect source responses (906 $\mathrm{msec}, S E=34)$ $[F(1,16)=0.67, p=.42]$. Behavioral results for the retrieval task are shown in Table 1 . The recognition hit rate was $83.1 \%(S D=6.9)$, and the false alarm (incorrect "new" response) rate was $9.4 \%(S D=7.3)$. These data indicate that less than $10 \%$ of the recognition hits were based on "lucky guesses," considering that false alarm rates provide an estimate of the guessing rates for hits (Snodgrass \& Corwin, 1988). Corrected recognition, after subtracting false alarms, was $73.7 \%(S D=$ 12.0), and this performance significantly differed from the chance level of $50 \%[F(1,16)=92.61, p<.001]$. To estimate the guessing rates for correct source judgments, these rates were also corrected by subtracting the false alarm rate. After correction, the source judgments of studied items significantly exceeded the chance level of $25 \%[F(1,16)=8.96, p=.009]$. Thus, after correcting for guessing (Rugg et al., 1998), veridical source memory was $\sim 37 \%$ for all correctly recognized old items and about $80 \%$ for the items that attracted correct source judgments. This performance pattern meant that sufficient trials were available to reliably estimate the brain responses elicited by recognized items associated with both correct and incorrect source judgments. The ANOVA for correct source 
Table 1

Performance During the Retrieval Session for Old and New Items

\begin{tabular}{lrrrrr}
\hline & \multicolumn{2}{c}{ Accuracy (\%) } & & \multicolumn{2}{c}{ RT } \\
\cline { 2 - 3 } \cline { 5 - 6 } & $M$ & $S D$ & & $M$ & $S D$ \\
\hline Old Items & & & & \\
$\quad$ Correct source responses & 46.2 & 10.9 & & 1,346 & 235 \\
$\quad$ Incorrect source responses & 36.9 & 9.7 & & 1,524 & 311 \\
$\quad$ Items judged as new & 11.2 & 7.0 & & 1,315 & 247 \\
New Items & & & & \\
$\quad$ Correct responses & 90.1 & 7.1 & & 1,082 & 121 \\
$\quad$ Incorrect responses & 9.4 & 7.3 & & 1,366 & 623 \\
\hline
\end{tabular}

Note-For old items, trials in which an incorrect judgment was made during encoding or in which no response was given were excluded (total exclusions $=5.7 \%$ ). For new items, trials in which no response was given were also excluded $(0.5 \%)$.

rates by the quadrants in which items were presented in the study phase was marginally significant $[F(3,48)=$ 2.93, $p=.05, \varepsilon=.87]$. However, the follow-up $t$ test with Bonferroni-corrected $p$ values (.008) for multiple comparisons showed no significant correct source rate differences between any of the quadrants. As depicted in Table 1, correct source responses were provided more quickly than incorrect source responses $[F(1,16)=18.85$, $p=.001]$. The RTs for correct source responses for the four response keys representing the different source locations during the test phase were not significantly different $[F(3,48)=1.05, p=.4, \varepsilon=.92]$.

\section{ERP Results}

Encoding. In Figure 2, the overall mean average ERP waveforms recorded in the encoding phase for subsequent correct and incorrect source judgments are shown. The mean numbers of trials were $29.8(S D=9.3)$ and $25.7(S D=8.6)$ for subsequent correct and incorrect responses, respectively. The outcomes of the global and specific ANOVAs are shown in Table 2, along with the interactions that were significant according to follow-up post hoc analyses. The global ANOVAs were not significant for the early components with maximum amplitudes at 120,180 , and $350 \mathrm{msec}$ post-stimulus-onset, which were measured in the latency windows of $0-150,150-250$, and 250-480 msec, respectively (Figure 1). Significant subsequent memory effects were observed, according to the global ANOVAs, in the following four latency windows: 480-730, 730-950, 950-1,200, and 1,200-1,600 msec. None of these latency windows showed significant interactions between the factors response category and electrode site. In all of these latency windows, the amplitude was more positive for subsequent correct than for incorrect source responses. The global ANOVA for the last latency window $(1,600-2,000 \mathrm{msec})$ was not significant.

Between 480 and $730 \mathrm{msec}$, a positive component with maximum amplitude at $600 \mathrm{msec}$ post-stimulus-onset was measured. The outcome of the specific ANOVA carried out on data in this latency window was significant for the factor response category and for the interaction between the factors response category and anterior-posterior site. Post hoc analyses revealed that the amplitude for subsequent correct source responses differed from that for subsequent incorrect source responses only at frontal and central electrode sites. The next latency window (730-950 msec) was designated to measure the following negative component, peaking at approximately $850 \mathrm{msec}$ post-stimulus-onset. The specific ANOVA computed in this latency window was significant only for the factor response category. After this negative component, a sustained positive component predominated in the encoding waveforms; this long-lasting component ended approximately $300 \mathrm{msec}$ before the end of the epoch in most of the electrode sites. Three consecutive latency windows (950-1,200, 1,200-1,600, and 1,600-2,000 msec) were employed to measure this sustained component, but only the first two were significant in the global ANOVAs. The specific ANOVA carried out in the first latency window (950-1,200 msec) was significant for the factor response category, as well as for the interactions between response category and anterior-posterior site and between response category, anterior-posterior site, and hemisphere. Post hoc analyses revealed that, at these latencies, subsequent memory effects were observed bilaterally at frontal electrode sites (F7, F3, F8, F4) and only in the right hemisphere at central electrode sites $(\mathrm{C} 4, \mathrm{~T} 8)$. For the following latency window $(1,200-1,600 \mathrm{msec})$, only the factor response category was significant.

The scalp topography analysis computed on difference scores between subsequent correct and subsequent incorrect source responses (Figure 3 ) included the two factors latency window (4 levels; amplitude effects were significant) and electrode site (28 levels). This ANOVA was significant for latency window $[F(3,48)=96.89, p<.001$, $\varepsilon=.71]$, but no significant interaction was observed of this factor with electrode site.

Retrieval. Figure 4 depicts the grand average ERPs recorded during retrieval for correctly recognized items attracting correct and incorrect source judgments, as well as for correct "new" responses. The mean numbers of epochs included in each of these response categories were 25.4 $(S D=12.9), 25.5(S D=9.7)$, and $25.2(S D=7.3)$, respectively. The global ANOVAs performed on the retrieval data (Table 3 ) were significant for the factor response category in all of the latency windows $(150-250,250-350,350-470$, $470-800,800-1,200,1,200-1,600$, and $1,600-2,000 \mathrm{msec})$ except the first one $(0-150 \mathrm{msec})$ and for the interaction between response category and electrode site in the latency windows of 470-800 and 800-1,200 msec. Table 3 shows the results of the following specific ANOVAs, conducted on the latencies at which effects were significant, as well as the significant interactions from subsequent post hoc tests. Between 150 and $250 \mathrm{msec}$, a component peaking at $180 \mathrm{msec}$ post-stimulus-onset was measured, which was characterized as being positive at anterior electrode sites but negative at posterior sites (Figure 1). The specific ANOVA computed on data from this latency window was significant for the factor response category. Post hoc analyses revealed that the amplitude for correct source responses was significantly more positive than the amplitude for correct "new" responses. In the following two latency windows (250-350 and 350-470 msec), a positive component peaking at $300 \mathrm{msec}$ and a negative 


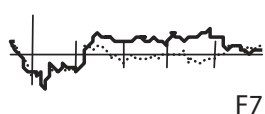

F7
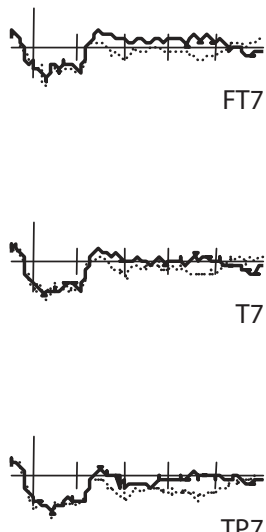

TP7
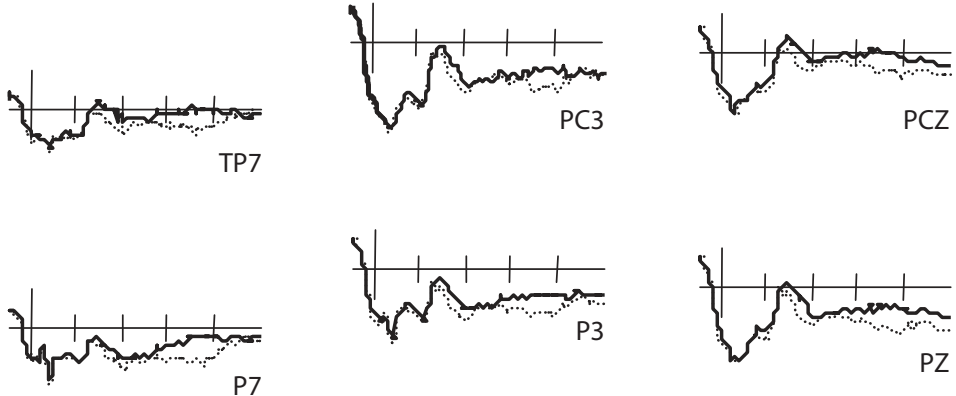

PCZ

PZ
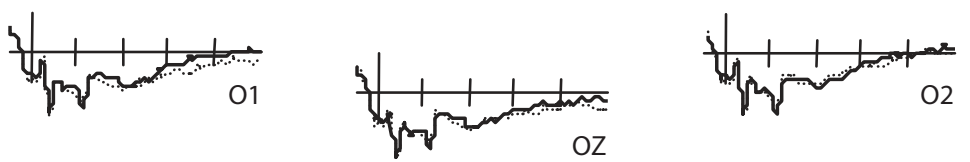

$\mathrm{OZ}$
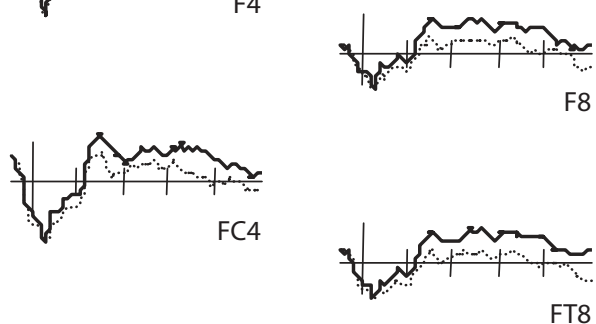

FT8
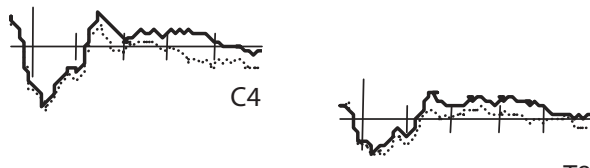

T8

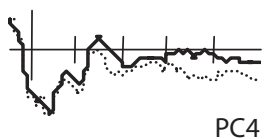

PC4
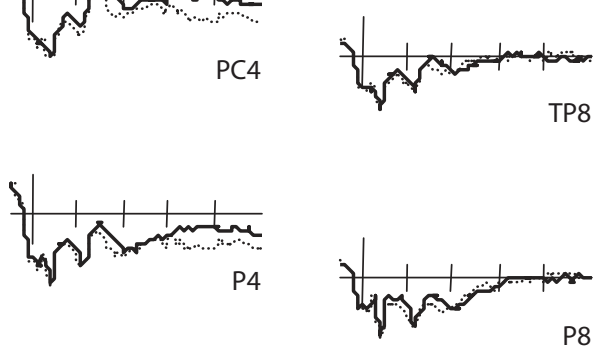

P8
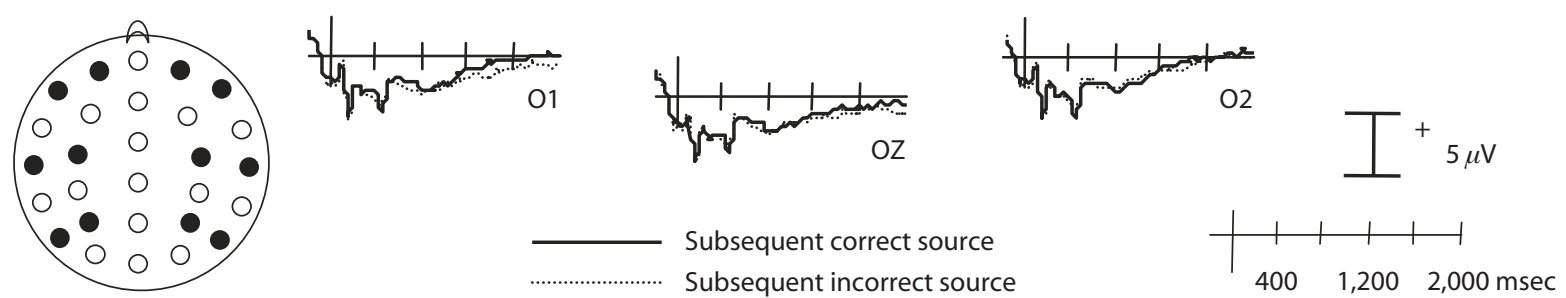

Figure 2. Grand average ERP waveforms recorded in the complete set of 28 electrode sites during encoding for subsequent correct and incorrect source judgments. The electrode sites selected for the specific analyses are indicated by the black filled circles in the insert.

component with maximum amplitude at approximately $430 \mathrm{msec}$ post-stimulus-onset were measured, respectively. The outcomes of the specific ANOVAs were significant for response category for both of these components. Post hoc comparisons indicated that the mean amplitudes of both components were significantly more positive for correct source responses than for either incorrect source responses or correct "new" responses, but that these last two categories did not differ significantly. The two subsequent components observed in the retrieval waveforms consisted of a prominent positive component peaking at approximately $600 \mathrm{msec}$ post-stimulus-onset, measured between 470 and $800 \mathrm{msec}$, and a negative component with maximum amplitude at $950 \mathrm{msec}$, measured between 800 and 1,200 msec. For both latency windows, the specific ANOVAs were significant for both response category and the interaction between response category and anterior- posterior site. The results of the follow-up post hoc tests were also similar for both latency windows. These tests revealed that the amplitude for correct source responses was more positive than those for incorrect source responses and correct "new" responses. This larger positive amplitude for correct source responses than for the other two response types was present at anterior, central, and posterior sites. In addition, the amplitude for incorrect source responses was more positive than the amplitude for correct "new" responses, but only at anterior electrode sites (F7, F3, F4, F8). The following sustained positive waveform was quantified in two consecutive time windows $(1,200-1,600$ and 1,600-2,000 msec). The specific ANOVA carried out in the latency window from 1,200 to $1,600 \mathrm{msec}$ was significant for response category. Post hoc tests revealed that the amplitude for correct source responses was more positive than that for incorrect source responses, and also than that 
Table 2

Mean Amplitude Results for Encoding Data

\begin{tabular}{|c|c|c|c|c|c|c|}
\hline \multirow{3}{*}{$\begin{array}{l}\text { Window } \\
\text { (msec) }\end{array}$} & \multicolumn{3}{|c|}{ Global ANOVAs } & \multicolumn{3}{|c|}{ Specific ANOVAs } \\
\hline & \multirow{2}{*}{$\begin{array}{c}\mathrm{RC} \\
\frac{(d f=1,16)}{F}\end{array}$} & \multicolumn{2}{|c|}{$\begin{array}{c}\mathrm{RC} \times \mathrm{St} \\
(d f=27,432)\end{array}$} & \multirow{2}{*}{$\begin{array}{c}\mathrm{RC} \\
\frac{(d f=1,16)}{F}\end{array}$} & $\begin{array}{c}\mathrm{RC} \times \mathrm{AP} \\
(d f=2,32)\end{array}$ & $\begin{array}{c}\mathrm{RC} \times \mathrm{AP} \times \mathrm{H} \\
(d f=2,32)\end{array}$ \\
\hline & & $F$ & $\varepsilon$ & & $F$ & $F$ \\
\hline $0-150$ & 0.57 & 0.29 & .09 & & & \\
\hline $150-250$ & 0.46 & 0.69 & .10 & & & \\
\hline $250-480$ & 2.70 & 0.64 & .14 & & & \\
\hline $480-730$ & $11.52^{* *}$ & 2.17 & .15 & $10.36^{* *}$ & $\begin{array}{l}4.18^{*} \quad .59 \\
\text { Anterior: S-I } \\
\text { Central: S-I }\end{array}$ & \\
\hline $730-950$ & $5.07^{*}$ & 1.37 & .09 & $5.90^{*}$ & & \\
\hline $950-1,200$ & $5.43^{*}$ & 1.41 & .16 & $5.60^{*}$ & $\begin{array}{ll}4.02^{*} & .64 \\
\text { Anterior: } & \text { S-I }\end{array}$ & $\begin{array}{l}3.69^{*} \quad .93 \\
\text { Anterior left: } \mathrm{S}-\mathrm{I} \\
\text { Anterior right: } \mathrm{S}-\mathrm{I} \\
\text { Central right: } \mathrm{S}-\mathrm{I}\end{array}$ \\
\hline $\begin{array}{l}1,200-1,600 \\
1,600-2,000\end{array}$ & $\begin{array}{c}11.12^{* *} \\
0.87\end{array}$ & $\begin{array}{l}0.95 \\
0.82\end{array}$ & $\begin{array}{l}.14 \\
.11\end{array}$ & $9.92^{* *}$ & & \\
\hline
\end{tabular}

Note-The global ANOVAs included 28 electrodes, and results for all time windows are reported. The specific ANOVAs included 12 electrode sites, and results are presented only when they are significant, along with significant interactions based on post hoc tests. RC, response category (S, subsequent correct source response; I, subsequent incorrect source response); St, electrode site; AP, anteriorposterior site (anterior, central, posterior); $\mathrm{H}$, hemisphere (left, right). ${ }^{*} p<.05 .{ }^{* *} p<.01$.

for correct "new" responses. In the last latency window $(1,600-2,000 \mathrm{msec})$, the specific ANOVA did not reach significant results, although the global ANOVA had.

The scalp topographies over time for each tested memory effect are depicted in Figure 5. The results of the analyses conducted on these memory effects are reported only when the factor electrode site was significant. The first analysis was computed for two memory effectscorrect source - incorrect source responses and incorrect source - correct "new" responses - and included the factors memory effect, latency window at which effects were significant (470-800 and 800-1,200 msec), and electrode site (28 levels). The results were significant for the memory effect $\times$ electrode site interaction $[F(27,432)=6.78$, $p=.002, \varepsilon=.09]$. Post hoc analysis revealed that correct source - incorrect source responses differed significantly from incorrect source - correct "new" responses at electrodes CPZ, PZ, OZ, CP3, P3, P4, and O1. The second ANOVA was computed for the factors memory effect (difference scores for incorrect source - correct "new" responses and correct source - correct "new" responses), latency window at which effects were significant (470-800 and 800-1,200 msec), and electrode site $(28$ levels). The memory effect $\times$ latency window $\times$ electrode site interaction $[F(27,432)=2.73, p=.03, \varepsilon=.17]$ was significant. Post hoc analyses revealed that the two memory effects were significantly different in both latency windows at all electrode sites. The third analysis was computed for memory effect (difference scores for correct source - incorrect source responses and correct source - correct "new" responses), latency window at which effects were significant $(250-350,350-470$, $470-800,800-1,200$, and 1,200-1,600 msec), and electrode site (28 levels). The interactions latency window $\times$ electrode site $[F(108,1728)=6.41, p<.001, \varepsilon=.06]$ and memory effect $\times$ latency window $\times$ electrode site $[F(108,1728)=3.60, p=.001, \varepsilon=.07]$ were significant. Post hoc analyses showed that these memory effects had different scalp distributions at all latency windows; for both memory effects, scalp topography changed across all latency windows, except between the windows at 470-800 msec and 800-1,200 msec.

\section{DISCUSSION}

The source memory paradigm employed in the present experiment was previously used in an event-related fMRI study by Cansino et al. (2002). The behavioral performance patterns are quite similar in both experiments, except concerning two issues. First, lower rates of cor-

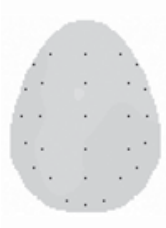

$0-150$

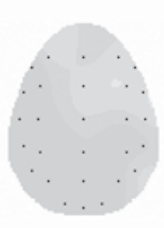

$150-250$

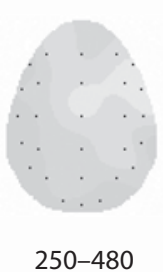

$250-480$
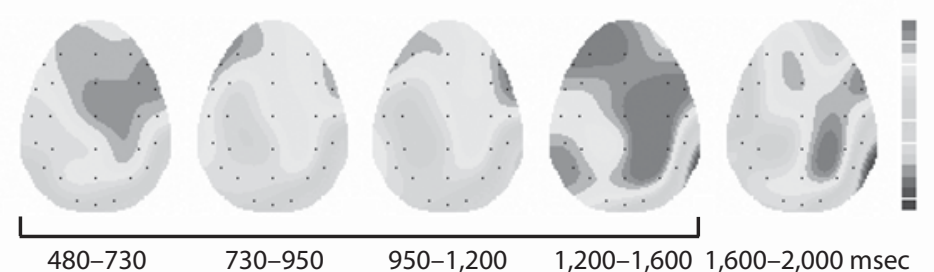

$+2.0 \mu \mathrm{V}$

$950-1,200$

Figure 3. Topographic maps recorded at each latency window during encoding, depicting the time course of the difference between subsequent correct and incorrect source judgments. Latency windows in which effects were significant are marked with horizontal lines. 


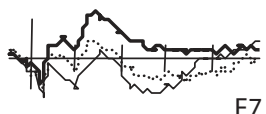

F7

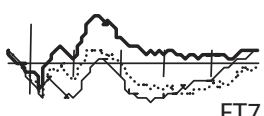

FT7

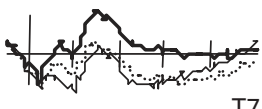

T7

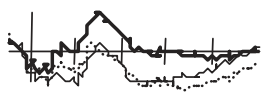

TP7

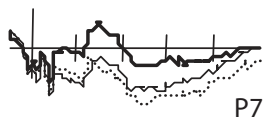

P7

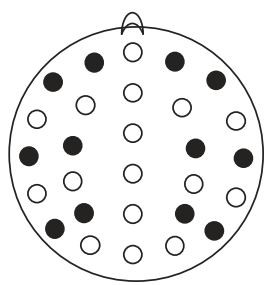

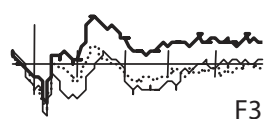

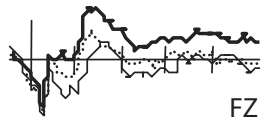

FZ

F3
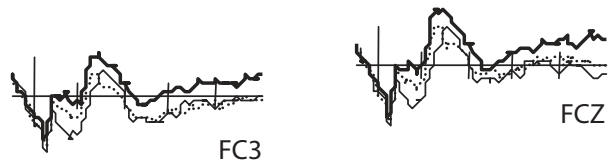

FCZ

FC3

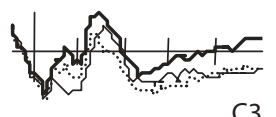

C3

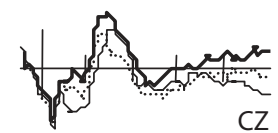

CZ

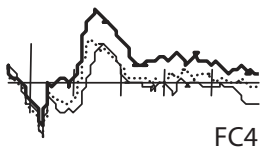

FC4

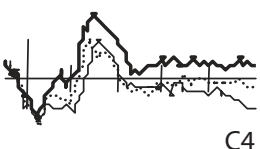

C4

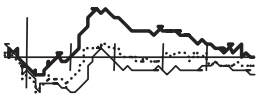

T8
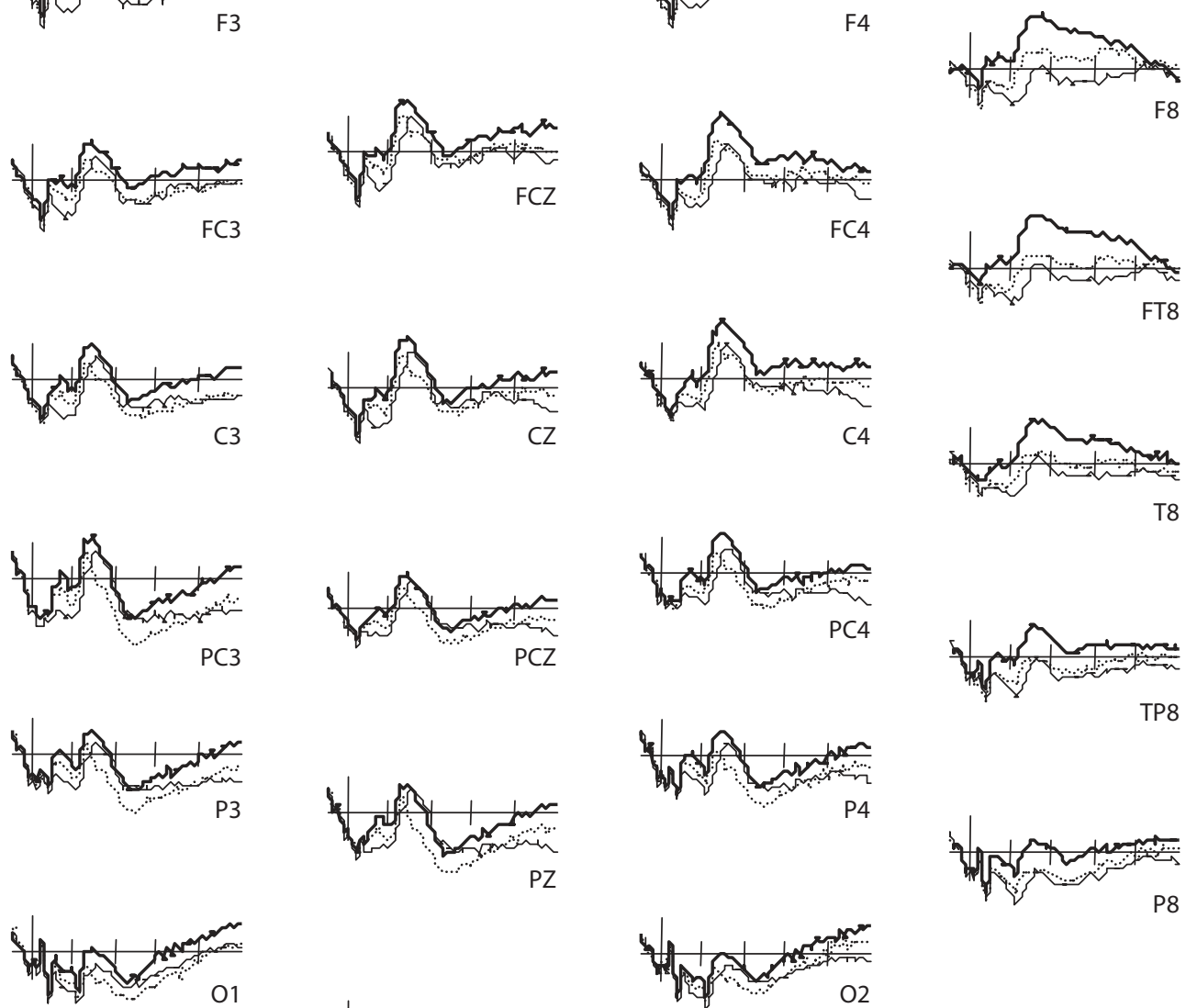

PZ
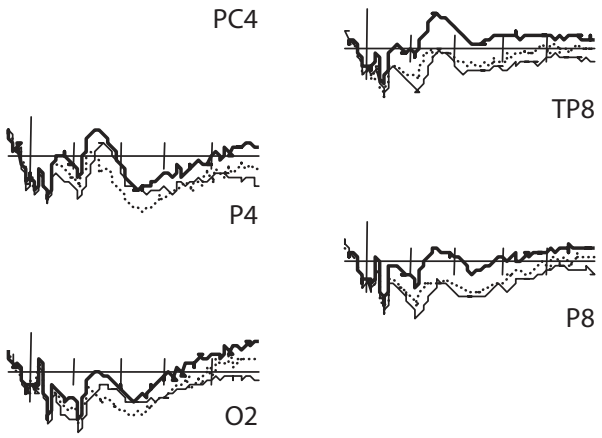
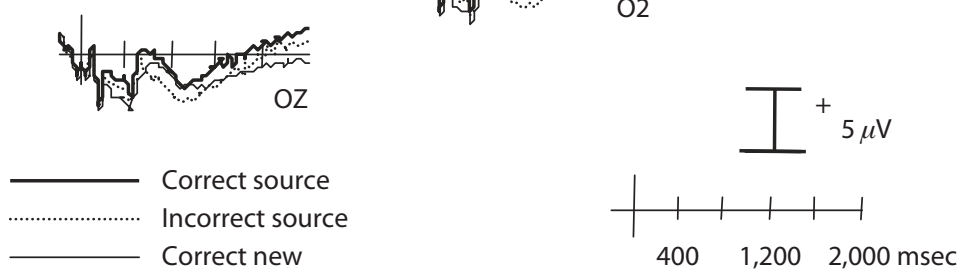

Figure 4. Grand average ERP waveforms recorded in the complete set of 28 electrode sites during retrieval for correct source judgments, incorrect source judgments, and correct "new" responses. The electrode sites selected for the specific analyses are indicated by the black filled circles in the insert.

rect source responses were observed in the present study $(46.2 \%)$ than in the previous one $(60.7 \%)$. This accuracy drop of $\sim 15 \%$ corresponds closely to the increase in the number of items employed in the ERP experiment, which was necessary in order to fulfill the number of epochs required to maintain a reliable signal-to-noise ratio. For this reason, 120 stimuli were employed in the present experiment, as compared with 90 in the fMRI study. This 33\% increment in memory load was related to a corresponding decrease of $\sim 24 \%$ in correct source memory judgments. Notably, neither item recognition $(87 \%$ and $83 \%$, respectively, in the fMRI and ERP experiments) nor false alarm rates $(6 \%$ and $9 \%$, respectively) were affected by this increase in memory load. These results clearly indicate the greater vulnerability of source memory information to memory load, as compared with information about the item or event itself. Second, reaction times (RTs) for correct and incorrect source responses were $190 \mathrm{msec}$ longer in the ERP than in the fMRI experiment. This difference cannot be attributed to technical procedures, since RTs for new items only differed by an average of $35 \mathrm{msec}$ between the experiments. Therefore, longer RTs in the ERP than in the fMRI experiment could be due to an increase in uncertainty during responding as the number of items to remember increased, along with the number of contexts, rendering the memory task more difficult. Despite these performance differences, the source memory paradigm remained a suitable one for reliably estimating brain activity related to the successful encoding and retrieval of source memory, since correct source judgments significantly exceeded chance levels, even after correcting for guessing, and since the four-choice source procedure permitted us 
Table 3

Mean Amplitude Results for Retrieval Data

\begin{tabular}{|c|c|c|c|c|c|c|c|}
\hline \multirow{3}{*}{$\begin{array}{l}\text { Window } \\
\text { (msec) }\end{array}$} & \multicolumn{4}{|c|}{ Global ANOVAs } & \multicolumn{3}{|c|}{ Specific ANOVAs } \\
\hline & \multicolumn{2}{|c|}{$\begin{array}{c}\mathrm{RC} \\
(d f=2,32)\end{array}$} & \multicolumn{2}{|c|}{$\begin{array}{c}\mathrm{RC} \times \mathrm{St} \\
(d f=54,864)\end{array}$} & \multicolumn{2}{|c|}{$\begin{array}{c}\mathrm{RC} \\
(d f=2,32)\end{array}$} & $\begin{array}{l}\mathrm{RC} \times \mathrm{AP} \\
(d f=4,64)\end{array}$ \\
\hline & $F$ & $\varepsilon$ & $F$ & $\varepsilon$ & $F$ & $\varepsilon$ & $F$ \\
\hline $0-150$ & 2.99 & .92 & 0.80 & .09 & & & \\
\hline $150-250$ & $6.80^{* *}$ & .98 & 1.10 & .08 & $\begin{array}{l}6.85^{* *} \\
\mathrm{~S}-\mathrm{N}\end{array}$ & .91 & \\
\hline $250-350$ & $22.15^{* * *}$ & .96 & 1.74 & .08 & $\begin{array}{l}19.37^{* * *} \\
\text { S-I } \\
\text { S-N }\end{array}$ & .92 & \\
\hline $350-470$ & $17.94^{* * *}$ & .98 & 1.30 & .08 & $\begin{array}{l}16.62^{* * *} \\
\text { S-I } \\
\text { S-N }\end{array}$ & .99 & \\
\hline $470-800$ & $20.65^{* * *}$ & .79 & $3.16^{*}$ & .08 & $\begin{array}{l}20.54^{* * *} \\
\text { S-I } \\
\text { S-N }\end{array}$ & .84 & $\begin{array}{l}\text { 5.28** } .70 \\
\text { Anterior: S-I } \\
\text { Anterior: S-N } \\
\text { Anterior: I-N } \\
\text { Central: S-I } \\
\text { Central: S-N } \\
\text { Posterior: S-I } \\
\text { Posterior: S-N }\end{array}$ \\
\hline $800-1,200$ & $13.73^{* * *}$ & .87 & $3.05^{*}$ & .08 & $\begin{array}{l}12.06^{* * *} \\
\text { S-I } \\
\text { S-N }\end{array}$ & .82 & $\begin{array}{l}7.58^{* * *} .54 \\
\text { Anterior: S-I } \\
\text { Anterior: S-N } \\
\text { Anterior: I-N } \\
\text { Central: S-I } \\
\text { Central: S-N } \\
\text { Posterior: S-I } \\
\text { Posterior: S-N }\end{array}$ \\
\hline $1,200-1,600$ & $9.76^{* * *}$ & .86 & 1.08 & .09 & $\begin{array}{l}7.40^{* *} \\
\text { S-I } \\
\text { S-N }\end{array}$ & .90 & \\
\hline $1,600-2,000$ & $5.38^{*}$ & .79 & 1.02 & .10 & & & \\
\hline
\end{tabular}

Note-The global ANOVAs included 28 electrodes, and results for all time windows are reported. The specific ANOVAs included 12 electrode sites, and results are presented only when they are significant, along with significant interactions based on post hoc tests. RC, response category (S, correct source judgment; I, incorrect source judgment; $\mathrm{N}$, correct "new" response); St, electrode site; AP, anterior-posterior site (anterior, central, posterior). ${ }^{*} p<.05 . \quad{ }^{* *} p<.01 . \quad{ }^{* * *} p<.001$.

to obtain sufficient proportions of correct and incorrect source trials.

\section{Encoding}

Subsequent memory effects have been interpreted as reflecting elaborative processes or deeper and more extensive item processing at the time of encoding, which then enhances the possibility of remembering the information in a later memory task (for reviews, see Friedman \& Johnson, 2000; Rugg, 1995). The present study reveals that subsequent memory effects for specific contextual information can also be recorded as for remember judgments (Duarte et al., 2004; Friedman \& Trott, 2000; Mangels et al., 2001), allowing a further examination of whether or not subsequent memory effects for specific source information and remember judgments share similar brain activity. Both procedures elicited subsequent memory effects that started somewhere between 300 and $500 \mathrm{msec}$, with variations probably due to different stimulus exposure times. The offset times of these effects in the Mangels et al. study can be compared with those in the present study, in which long-lasting epochs $(2,000 \mathrm{msec})$ were analyzed. In the Mangels et al. study, subjects were engaged in one of three attention conditions during encoding (focused attention, easy divided attention, and difficult divided attention). In their analyses with data separated for conditions of focused attention and easy divided attention when enough trials were available, items subsequently recalled freely and assigned a remember judgment were collapsed with items subsequently remembered but not recalled. This combined category $(\mathrm{R})$ was compared with items given a know judgment and with items subsequently missed. Interestingly, subsequent memory effects were reliable only in the easy divided attention condition, but not with focused attention, which is the condition more equivalent to that employed in the present study. The window of significant differences between their R category and know judgments $(500-1,000 \mathrm{msec})$ lasted $600 \mathrm{msec}$ less than in the present study $(480-1,600 \mathrm{msec})$, probably because their subjects also had to allocate resources to perform the secondary task.

The high recognition levels in the present study preclude the possibility of also comparing brain activity related to items subsequently missed. However, previous studies have already compared missed items with know judgments, pro- 

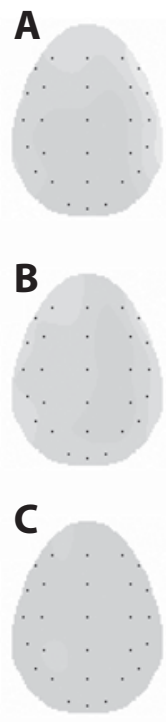

$0-150$
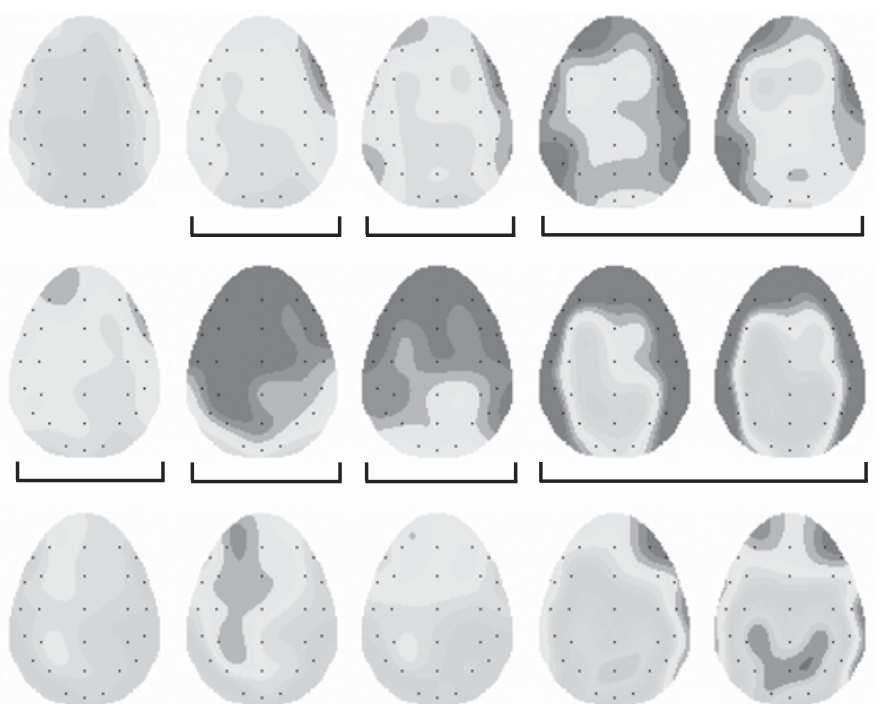

$150-250$

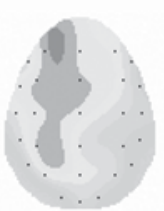

250-350

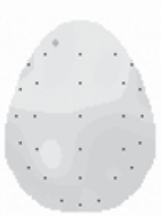

$350-470$

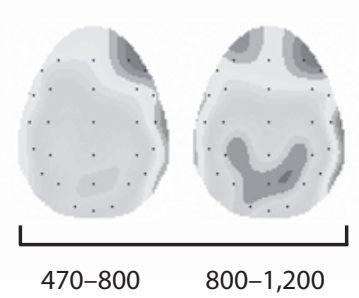

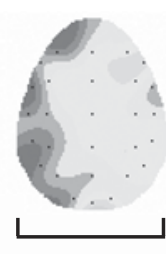
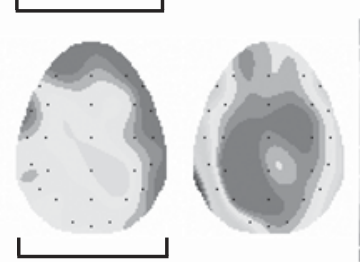

$+3.0 \mu \mathrm{V}$
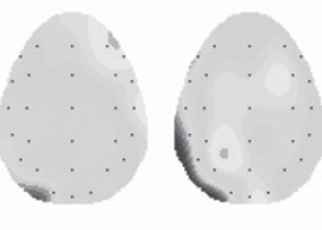

$1,200-1,6001,600-2,000$ msec

Figure 5. Topographic maps recorded at each latency window during retrieval, depicting the time courses of the differences between (A) correct and incorrect source judgments, $(B)$ correct source judgments and correct "new" responses, and (C) incorrect source judgments and correct "new" responses. Latency windows in which effects were significant are marked with horizontal lines, and the length of these lines indicates latency windows in which scalp topographies remained the same (long lines) or changed significantly (separate lines).

viding evidence of brain activity at encoding that predicts memory associated with familiarity processes. The most consistent finding is that subsequent memory effects for familiarity processes were observed during the first $500 \mathrm{msec}$ post-stimulus-onset, whereas recollection depended on brain activity after these latencies (Duarte et al., 2004; Mangels et al., 2001). The present results closely correspond to these findings, since the subsequent memory effects observed for source recollection started $\sim 500 \mathrm{msec}$ after stimulus presentation. Thus, the previous and present experiments support the proposal that successful encoding of a subsequent recollection experience requires further elaborative processes than does encoding for subsequent recognition on the basis of familiarity processes. Moreover, the fact that the subsequent memory effects for source information in the present study lasted longer than the effects observed for remember judgments indicates that recollecting the specific spatial context requires further processing beyond that for only providing a remember judgment, which does not force the subject to offer any evidence of the actual recollection experience. Indeed, the retrieval of specific source information might be a more demanding recollection experience than free item recall, which in turn is more challenging than a remember judgment. Support for this interpretation comes from the fact that only $\sim 55 \%$ of the remember items were ultimately freely recalled in Mangels et al.'s study.

A common finding in most of the studies searching for subsequent memory effects for remember versus know responses and, in the present study, for correct versus incorrect source responses is that a subsequent recollection experience requires bilateral frontal and posterior activity. However, Duarte et al. (2004) did not observe pos- terior activity. The most prominent region manifesting a subsequent memory effect in our previous fMRI study (Cansino et al., 2002), which employed the same paradigm as the present study, was the right lateral occipital cortex. The activity in this region was interpreted as the greater perceptual process produced by items and their context, which could be more effectively encoded into episodic memory. In the present ERP study, the most posterior regions showing subsequent memory effects were located at parietal sites $(1,200-1,600 \mathrm{msec})$. However, the lack of spatial resolution of the ERP technique does not allow us to deduce whether this activity corresponds to the posterior activity observed in the previous fMRI study. The present results do show that frontal activity takes place before posterior activity in order to ensure subsequent spatial recollection, information that was not available with the fMRI technique. The fact that successful encoding of specific contextual information depends first on frontal and second on posterior activity may bring support to the notion that the frontal cortex participates through executive functions or top-down processes at encoding, thus coordinating which sensory and contextual components of an episodic representation should be integrated (Squire \& Kandel, 1999).

Less consistent among studies is the right-lateralized activity observed at frontal sites (Duarte et al., 2004), and at central locations in the present study. In some fMRI studies, researchers have reported that lateralized brain activity may be related to the kind of information that is encoded (Cansino et al., 2002; Kelley et al., 1998; Wagner et al., 1998): Left brain activity more often has been related to verbal information, whereas right or bilateral activity has 
been observed mainly during encoding of pictorial stimuli. Duarte et al. also presented images randomly in two different positions on the screen during encoding, as in the present study, in which four different positions were employed. This similarity between the procedures suggests that the spatial context may have been implicitly encoded in both studies. Even though the subjects in the Duarte et al. experiments were not explicitly asked to retrieve the spatial context, because the remember-know procedure was employed, the subjects could have benefited from spatial contextual information for solving the task. Thus, it is not possible to rule out, given the present information, whether the activity at scalp locations in the right hemisphere observed both by Duarte et al. and in the present study was due to the pictorial stimuli or to the spatial context in which the stimuli were presented. Further research will be necessary in order to elucidate whether right-lateralized brain activity during encoding is related to specific contextual information, the material to be memorized, or a more generic recollection-encoding process independent of the specific information to be encoded.

\section{Retrieval}

Differences between correct source judgments and correct "new" responses have been used extensively in order to examine brain activity for "recollection"; however, this comparison does not exclude the contribution of responses on the basis of familiarity processes (Friedman \& Johnson, 2000). When this comparison has been carried out on data obtained from retrieval source memory tasks (Leynes et al., 2003; Li et al., 2004; Mark \& Rugg, 1998; Rugg et al., 1998; A. P. R. Smith et al., 2004; Trott et al., 1997; Wegesin et al., 2002; Wilding, 1999, 2000; Wilding \& Rugg, 1996, 1997), two electrophysiological memory effects have consistently been observed: the "left parietal" and "right frontal" effects. Both effects are characterized by greater positive-amplitude waveforms for correct source responses than for correct "new" judgments. The first effect commonly occurs between approximately 400 and $900 \mathrm{msec}$, and the second between approximately 800 and $1,400 \mathrm{msec}$, each with different scalp topographies. However, these effects have also been recorded as having wide bilateral distributions (Johnson et al., 1997; Leynes et al., 2003), or even with the right frontal effect missing (Cycowicz \& Friedman, 2003). The left parietal effect has been related to recollection, because its magnitude varies as a function of the quantity and quality of the episodic information retrieved (Wilding, 2000), whereas the meaning of the right frontal effect is still controversial. Some authors have proposed that the latter effect is an index of successful retrieval of source information, since its activity was enhanced during correct source trials (Wilding \& Rugg, 1996, 1997); others, however, have provided evidence against this proposal (Ranganath \& Paller, 1999). This effect has also been related to postretrieval processing or further monitoring of retrieved episodic information (Rugg \& Wilding, 2000).

Both effects were evident in the present data in the comparisons of correct and incorrect source responses and of correct source responses and correct "new" judgments, although the effects did not show an asymmetrical, but rather a widespread, distribution. In a working memory task in which object and spatial memory were tested under similar conditions, Mecklinger (1998) found that frontal activity was right-lateralized during the recognition of object forms but bilateral during the recognition of spatial locations. Although this finding coincides with the symmetrical frontal effect observed in the present study for spatial contextual retrieval, it is also possible that lateralized activity was missing here because we employed linked references at recording; it has been pointed out that this procedure may affect the current flow and, hence, modify the recorded activity (Miller, Lutzenberger, \& Elbert, 1991), for example by reducing hemisphere asymmetry.

The electrophysiological difference recorded between correct and incorrect source judgments allowed us to examine the brain activity related to source memory recollection. The major discrepancy between the two previous studies that have analyzed this comparison is that frontal amplitude differences between the two response categories were only observed by Wilding (1999), not by Senkfor et al. (2002). In the latter study, waveforms for correct new items were not included, which complicates the interpretation of their data. The present results coincide with those of Wilding (1999) and accumulate evidence for the proposal that the frontal memory effect is related to successful recollection processes. Although Wilding (1999) concluded that the frontal effect reflects postretrieval monitoring processes, independently of whether retrieval is successful or not, the present data show that the frontal electrophysiological brain activity actually reflects multiple processes, since we found it was related to successful retrieval, indicated by the significant difference observed between correct and incorrect source judgments. The classical parietal memory effect was also related to recollection processes in the present study, as has been observed as well in previous experiments (Senkfor et al., 2002; Wilding, 1999), since differences between correct and incorrect source responses in our study were significant at posterior sites, whereas activity related to item recognition without source recollection, as analyzed by the comparison between incorrect source responses and correct "new" judgments, did not differ at these electrode sites.

Some similarity in brain activity is expected when comparing the differences between correct and incorrect source judgments with those between correct source and correct "new" responses, since in the second comparison activity related to recollection is included along with that related to familiarity. Our data clearly demonstrate this overlapping activity, since both comparisons elicited significantly widespread amplitude differences between 250 and 1,600 msec after stimulus onset. Moreover, scalp topography for both effects changed significantly across the same latency windows but differed significantly at all latency windows, indicating that distinguishable underlying neural activity was responsible for both effects. Another notable distinction was that amplitude differences between correct source and correct "new" response trials started $100 \mathrm{msec}$ earlier than amplitude differences between correct and incorrect source trials. The early amplitude differ- 
ence (150-250 msec) between trials with correct source and correct "new" responses may be related to an orientation process elicited by the initial discernment between novel and old stimuli, rather than reflecting early retrieval processes. A similar early effect was reported by Tsivilis, Otten, and Rugg (2001), which they interpreted as indicating that studied stimuli were sufficiently identified to start being processed. Another explanation suggests that this effect is elicited by priming processes, which use different resources than those employed for explicit memory processes (Hamann \& Squire, 1997).

Except for the study by Wilding (1999), differences between incorrect source and correct "new" judgments have not been examined before. This contrast allows for examining the activity related to item recognition accompanied by a lesser amount of source information, which may share some similarities with memory based on familiarity. In Wilding's (1999) study, as in the present one, greater positive waveforms were recorded for incorrect source judgments than for correct "new" responses at frontal sites, but he recorded this effect at later latencies $(1,400-1,900 \mathrm{msec})$ than in the present study $(470-1,200)$. The most frequent memory effect identified during familiarity processes has been medial frontal activity at early latencies, between approximately 400 and $600 \mathrm{msec}$ (see, e.g., Curran, 2000; M. E. Smith, 1993). Although there are remarkable latency differences between these studies, the anterior distribution of this effect is notably similar, suggesting that timing differences are probably due to the fact that retrieval source memory tasks are highly complex. This interpretation is supported by the long average response times observed in Wilding's (1999) study $(1,803 \mathrm{msec})$ and in the present study $(1,524 \mathrm{msec})$ for incorrect source responses. Some authors have suggested that familiarity processes occur earlier than source or recollection decisions (Van Petten, Senkfor, \& Newberg, 2000), whereas others have provided evidence that both types of processes take place concurrently (Senkfor \& Van Petten, 1998). The present data and those of Wilding (1999) show that these processes may take place simultaneously at some point, probably when the brain is still trying to retrieve the source but finally fails, since the differences between all conditions were significant when incorrect source and correct "new" judgments differed in the present study.

The scalp topography for accurate spatial recollection (correct minus incorrect source judgments) differed from that for spatial recollection failure (incorrect source minus correct "new" responses). This difference did not occur at frontal areas but did at parietal and left occipital sites. Thus, frontal activity arises from common brain regions for these two processes, since only quantitative differences were evident (Figure 5), probably due to the less intense frontal activity required to accomplish the task of recognizing an item without retrieving its spatial location than of recognizing an item and accurately retrieving its spatial location. However, reliable qualitative differences distinguish both processes at parietal sites. In fact, previous fMRI studies (Davachi, Mitchell, \& Wagner, 2003; Henson, Rugg, Shallice, Josephs, \& Dolan, 1999) have provided empirical evidence that supports different neural correlates for recollection and familiarity.

In summary, successful source memory encoding of specific contextual, such as spatial, information, as assessed by the ERP technique, requires activity from frontal and right central regions that occurs $\sim 500 \mathrm{msec}$ after the stimulus has been presented. Thus, subsequent memory effects for specific source information seem to require time to build up, probably because they take place once the stimulus has been identified, processed, and integrated into its specific source attributes.

Episode retrieval is thought to involve several underlying subprocesses that start from a cue, which may be external or internal and triggers an appropriate state of mind or retrieval mode; when the cue shares some similarity with episodic memory representations, the previous episodic experience may or may not be successfully retrieved (Rugg \& Wilding, 2000). The present data offer evidence of the brain activity underlying retrieval success: (1) the amplitude difference from 150 to $250 \mathrm{msec}$ between correct source and correct "new" responses may correspond to the initial subprocess, elicited by an external cue, that introduces the retrieval mode; (2) afterward, source retrieval processes predominate, judging from the amplitude difference observed between correct and incorrect source judgments and the fact that this activity coincides with the early "left parietal" effect, which has been associated with recollection processes; (3) after $500 \mathrm{msec}$ and concurrently with source recollection, brain activity related to unsuccessful spatial source retrieval attempts may be present; and finally, (4) brain activity related to successful source memory retrieval emerges, and probably also postretrieval subprocesses used to verify the source memory decision, as reflected by the "right frontal" effect, which has been linked to retrieval success and monitoring processes.

\section{AUTHOR NOTE}

This study was supported by grants from CONACyT (46092-H) and the Universidad Nacional Autónoma de México (DGAPA PAPIIT IN300206). We are grateful to I. Pérez Montfort for revising the manuscript. Correspondence relating to this article may be sent to S. Cansino, Laboratorio de NeuroCognición, Facultad de Psicología, Universidad Nacional Autónoma de México, Apartado Postal 70-390, 04511 México D.F., México (e-mail: selene@servidor.unam.mx).

Note-This article was accepted by the previous editorial team, when John Jonides was Editor.

\section{REFERENCES}

Burgess, P. W., \& Shallice, T. (1996). Confabulation and the control of recollection. Memory, 4, 359-411.

Cansino, S., Maquet, P., Dolan, R. J., \& RugG, M. D. (2002). Brain activity underlying encoding and retrieval of source memory. Cerebral Cortex, 12, 1048-1056.

Curran, T. (2000). Brain potentials of recollection and familiarity. Memory \& Cognition, 28, 923-938.

Cycowicz, Y. M., \& Friedman, D. (2003). Source memory for the color of pictures: Event-related brain potentials (ERPs) reveal sensoryspecific retrieval-related activity. Psychophysiology, 40, 455-464.

Davachi, L., Mitchell, J. P., \& Wagner, A. D. (2003). Multiple routes to memory: Distinct medial temporal lobe processes build item and 
source memories. Proceedings of the National Academy of Sciences, 100, 2157-2162.

Duarte, A., Ranganath, C., Winward, L., Hayward, D., \& Knight, R. T. (2004). Dissociable neural correlates for familiarity and recollection during the encoding and retrieval of pictures. Cognitive Brain Research, 18, 255-272.

Fletcher, P. C., \& Henson, R. N. A. (2001). Frontal lobes and human memory: Insights from functional neuroimaging. Brain, 124, 849-881.

Friedman, D., \& Johnson, R., JR. (2000). Event-related potential (ERP) studies of memory encoding and retrieval: A selective review. Microscopy Research \& Technique, 51, 6-28.

Friedman, D., \& Trott, C. (2000). An event-related potential study of encoding in young and older adults. Neuropsychologia, 38, 542-557.

Gardiner, J. M., \& JAVA, R. I. (1993). Recognising and remembering. In A. F. Collins, S. E. Gathercole, M. A. Conway, \& P. E. Morris (Eds.), Theories of memory (pp. 163-188). Hillsdale, NJ: Erlbaum.

HamanN, S. B., \& SQuire, L. R. (1997). Intact perceptual memory in the absence of conscious memory. Behavioral Neuroscience, 111, 850-854.

Henson, R. N. A., Rugg, M. D., Shallice, T., Josephs, O., \& Dolan, R. J. (1999). Recollection and familiarity in recognition memory: An event-related functional magnetic resonance imaging study. Journal of Neuroscience, 19, 3962-3972.

Johansson, M., Stenberg, G., Lindgren, M., \& Rosén, I. (2002). Memory for perceived and imagined pictures: An event-related potential study. Neuropsychologia, 40, 986-1002.

Johnson, M. K., Kounios, J., \& Nolde, S. F. (1997). Electrophysiological brain activity and memory source monitoring. NeuroReport, 8, 1317-1320.

Kelley, W. M., Miezin, F. M., McDermott, K. B., Buckner, R. L., Raichle, M. E., Cohen, N. J., ET AL. (1998). Hemispheric specialization in human dorsal frontal cortex and medial temporal lobe for verbal and nonverbal memory encoding. Neuron, 20, 927-936.

Leynes, P. A., Bink, M. L., Marsh, R. L., Allen, J. D., \& May, J. C. (2003). Test modality affects source monitoring and event-related potentials. American Journal of Psychology, 116, 389-413.

Li, J., Morcom, A. M., \& RugG, M. D. (2004). The effects of age on the neural correlates of successful episodic retrieval: An ERP study. Cognitive, Affective, \& Behavioral Neuroscience, 4, 279-293.

Mangels, J. A., Picton, T. W., \& Craik, F. I. M. (2001). Attention and successful episodic encoding: An event-related potential study. Cognitive Brain Research, 11, 77-95.

MARK, R. E., \& RUGG, M. D. (1998). Age effects on brain activity associated with episodic memory retrieval: An electrophysiological study. Brain, 121, 861-873.

Mayes, A. R., \& Montaldi, D. (1999). The neuroimaging of long-term memory encoding processes. Memory, 7, 613-659.

McCarthy, G., \& WoOD, C. C. (1985). Scalp distributions of event-related potentials: An ambiguity associated with analysis of variance models. Electroencephalography \& Clinical Neurophysiology, 62, 203-208.

Mecklinger, A. (1998). On the modularity of recognition memory for object form and spatial location: A topographic ERP analysis. Neuropsychologia, 36, 441-460.

Miller, G. A., Lutzenberger, W., \& Elbert, T. (1991). The linkedreference issue in EEG and ERP recording. Journal of Psychophysiology, 5, 273-276.

Nadel, L., Ryan, L., Hayes, S. M., Gilboa, A., \& Moscovitch, M. (2003). The role of the hippocampal complex in long-term episodic memory. In T. Ono, G. Matsumoto, R. R. Llinas, A. Berthoz, R. Norgren, H. Nishijo, \& R. Tamura (Eds.), Cognition and emotion in the brain: Selected topics of the International Symposium on Limbic and Association Cortical Systems, Toyama, Japan 7-12 October 2002 (pp. 215-234). Amsterdam: Elsevier.

Ranganath, C., \& Paller, K. A. (1999). Frontal brain potentials during recognition are modulated by requirements to retrieve perceptual detail. Neuron, 22, 605-613.

RuGG, M. D. (1995). ERP studies of memory. In M. D. Rugg \& M. G. H. Coles (Eds.), Electrophysiology of mind: Event-related brain potentials and cognition (pp. 133-170). Oxford: Oxford University Press.

RugG, M. D., \& Henson, R. N. A. (2002). Episodic memory retrieval: An (event-related) functional neuroimaging perspective. In A. Parker, E. L.
Wilding, \& T. J. Bussey (Eds.), The cognitive neuroscience of memory: Encoding and retrieval (pp. 3-37). Hove, U.K.: Psychology Press.

RugG, M. D., Schloerscheidt, A. M., \& Mark, R. E. (1998). An electrophysiological comparison of two indices of recollection. Journal of Memory \& Language, 39, 47-69.

RugG, M. D., \& Wilding, E. L. (2000). Retrieval processing and episodic memory. Trends in Cognitive Sciences, 4, 108-115.

Semlitsch, H. V., Anderer, P., Schuster, P., \& Presslich, O. (1986). A solution for reliable and valid reduction of ocular artifacts, applied to the P300 ERP. Psychophysiology, 23, 695-703.

Senkfor, A. J., \& Van Petten, C. (1998). Who said what? An eventrelated potential investigation of source and item memory. Journal of Experimental Psychology: Learning, Memory, \& Cognition, 24, 1005-1025.

Senkfor, A. J., Van Petten, C., \& Kutas, M. (2002). Episodic action for real objects: An ERP investigation with perform, watch, and imagine action encoding tasks versus a non-action encoding task. Journal of Cognitive Neuroscience, 14, 402-419.

Smith, A. P. R., Dolan, R. J., \& RugG, M. D. (2004). Event-related potential correlates of the retrieval of emotional and nonemotional context. Journal of Cognitive Neuroscience, 16, 760-775.

Sмiтh, M. E. (1993). Neurophysiological manifestations of recollective experience during recognition memory judgments. Journal of Cognitive Neuroscience, 5, 1-13.

SnOdgrass, J. G., \& CorwIN, J. (1988). Pragmatics of measuring recognition memory: Applications to dementia and amnesia. Journal of Experimental Psychology: General, 117, 34-50.

Squire, L. R., \& Kandel, E. R. (1999). Memory: From mind to molecules. New York: Scientific American Library.

Trott, C. T., Friedman, D., Ritter, W., \& Fabiani, M. (1997). Item and source memory: Differential age effects revealed by event-related potentials. NeuroReport, 8, 3373-3378.

Tsivilis, D., Otten, L. J., \& RugG, M. D. (2001). Context effects on the neural correlates of recognition memory: An electrophysiological study. Neuron, 31, 497-505.

Tulving, E. (1972). Episodic and semantic memory. In E. Tulving \& W. Donaldson (Eds.), Organization of memory (pp. 381-403). New York: Academic Press.

Tulving, E. (1985). Memory and consciousness. Canadian Psychology, 26, 1-12.

Van Petten, C., Senkfor, A. J., \& Newberg, W. M. (2000). Memory for drawings in locations: Spatial source memory and event-related potentials. Psychophysiology, 37, 551-564.

Wagner, A. D., Poldrack, R. A., Eldridge, L. L., Desmond, J. E., Glover, G. H., \& Gabrieli, J. D. E. (1998). Material-specific lateralization of prefrontal activation during episodic encoding and retrieval. NeuroReport, 9, 3711-3717.

Wegesin, D. J., Friedman, D., Varughese, N., \& Stern, Y. (2002). Age-related changes in source memory retrieval: An ERP replication and extension. Cognitive Brain Research, 13, 323-338.

WILDING, E. L. (1999). Separating retrieval strategies from retrieval success: An event-related potential study of source memory. Neuropsychologia, 37, 441-454.

WILDING, E. L. (2000). In what way does the parietal ERP old/new effect index recollection? International Journal of Psychophysiology, 35, 81-87.

WiLDING, E. L., \& RUGG, M. D. (1996). An event-related potential study of recognition memory with and without retrieval of source. Brain, 119, 889-905.

WiLDING, E. L., \& RUGG, M. D. (1997). An event-related potential study of memory for words spoken aloud or heard. Neuropsychologia, 35, 1185-1195.

Yonelinas, A. P. (2002). The nature of recollection and familiarity: A review of 30 years of research. Journal of Memory \& Language, 46, 441-517.

Yonelinas, A. P., \& JACOBY, L. L. (1996). Noncriterial recollection: Familiarity as automatic, irrelevant recollection. Consciousness \& Cognition, 5, 131-141.

(Manuscript received January 10, 2007; revision accepted for publication December 18, 2007.) 